\title{
A metodologia Grounded Theory aplicada na pesquisa em música: um exemplo prático
}

Grounded Theory Methodology Applied to Research in Music: A Practical Example

Dr. Luciano da Costa Nazario* Universidade Federal do Rio Grande lucomposer@yahoo.com.br

*Professor da Universidade Federal do Rio Grande (RS), onde elabora projetos educativos com jovens e adultos em ambientes de ensino coletivo.

Submetido em 23/09/2018, Aprovado em 28/11/2018 


\section{Resumo}

Esse artigo apresenta os métodos, os procedimentos e os pressupostos epistemológicos da metodologia de pesquisa conhecida como Grounded Theory (ou teoria fundamentada), realizando um exame de sua aplicação prática em uma pesquisa de doutorado em música. Amplamente utilizada em ciências sociais nos Estados Unidos e países da Europa, o emprego dessa metodologia, principalmente na área da música, ainda é uma prática pouco comum no Brasil. Nesse sentido, buscamos evidenciar suas potencialidades e obstáculos nesse campo de estudo, apresentando alguns subsídios à pesquisadores interessados em investigar (e/ou teorizar) processos sociais na pesquisa em música. Como resultado, verificou-se que tal metodologia, se bem contextualizada com a investigação proposta, pode mostrar-se eficaz tanto no processo de coleta e análise dos dados quanto na implementação de uma teoria substantiva na área da música.

Palavras-chave: Teoria fundamentada. Pesquisa em música. Processos criativos.

\section{Abstract}

This paper presents methods, procedures and epistemological assumptions of a research methodology called Grounded Theory, along with a study of how it was applied to a doctoral research in music. This methodology is widely used in Social Sciences in the United States and European countries; however, it is still an uncommon practice in Brazil, especially in music studies. The main goal is to highlight the methodology potentials and drawbacks when applied in the field, by presenting some input to researchers who are interested in investigating (and/or theorizing) how social processes are worked out in music research. Findings show that such methodology, when applied to this research context, can be effective both for data collection and analysis process, as well as to the implementation of a substantive theory in the music field.

Keywords: Grounded Theory, Research in Music, Creative Processes 


\section{Introdução}

Esse artigo apresenta os procedimentos adotados na aplicação da metodologia Grounded Theory efetivada em uma pesquisa de doutorado financiada pela Fundação de Amparo à Pesquisa do Estado de São Paulo (FAPESP) e realizada na Universidade Estadual de Campinas (Unicamp) entre os anos de 2013 a 2017. Tal pesquisa teve por objetivo elaborar e sistematizar práticas de invenção musical ${ }^{1}$, aplicando-as junto a grupos de participantes com o intuito de responder a seguinte questão de pesquisa: $O$ desenvolvimento da criatividade ${ }^{2}$ pode ser alcançado através da prática de invenção musical? Caso positivo, como isso acontece? O eixo central dessa investigação consistiu, portanto, em visualizar e compreender os efeitos dessas práticas criativas junto aos grupos pesquisados.

De natureza qualitativa, esse estudo contou com o depoimento de 20 respondentes (músicos e estudantes de música), os quais foram informados quanto a natureza das atividades e assinaram o Termo de Consentimento Livre e Esclarecido (CAAE 35478314.4.0000.5404) dando as devidas permissões para participar da pesquisa. As atividades consistiram na realização de práticas de invenção musical, coletando, assim, informações referentes à eficiência dos exercícios e ao desenvolvimento criativo dos participantes. Os dados alusivos aos seus depoimentos e performances musicais foram registrados em áudio e vídeo (totalizando 48h47min de gravações) e analisados com vistas a formulação de uma teoria substantiva 3 . A Grounded Theory foi aplicada durante a coleta e análise desses dados, buscando-se compreender os fenômenos e as construções ${ }^{4}$ (ações e interações, significados atribuídos, estados afetivos etc.) realizadas pelos participantes durante a pesquisa empírica.

Esse artigo delimita-se em apresentar os fundamentos dessa metodologia e sua utilização no contexto dessa pesquisa. O objetivo aqui não é expor os resultados da investigação em si (teoria substantiva resultante desse trabalho), mas apresentar os caminhos percorridos por essa metodologia para chegarmos a tais resultados ${ }^{5}$. A aplicação

\footnotetext{
1 A invenção musical é entendida nesse trabalho como "uma ação criativa capaz de gerar (individualmente ou coletivamente) um produto final integral construído por meio de processos que levam a descobertas durante o fluxo musical" (NAZARIO, 2017, p. 20). Tal definição se deu através de discussões realizadas por este pesquisador e seu orientador, tendo como fundamento teórico a obra Imagination et invention, escrita pelo Francês Gilbert Simondon (SIMONDON, 2008, Apud MANNIS, 2014, p. 219).
}

20 conceito de criatividade adotado na tese de doutorado é discutido e detalhado por meio de uma extensa revisão bibliográfica. E síntese, entende-se criatividade como a habilidade em usar a flexibilidade cognitiva para resolver um problema/desafio ou criar algo.

3 Entende-se teoria substantiva como um modelo teórico que fornece uma 'teoria funcional' agindo em um contexto específico (DWIVEDl et al, 2009, p. 55).

$4 \quad$ Utilizamos "construções" por entendermos que suas falas e ações expressam muito mais do que uma simples resposta. Elas revelam uma construção sócio/cultural/histórica na qual a intervenção em que estão inseridos [neste caso, as atividades criativas] entra como mais um dos elementos em suas falas. Tais construções manifestam não apenas a subjetividade do indivíduo, pois o ser humano, apesar de ser único, contém a totalidade social expressa em suas ações, pensamentos e sentimentos. Nesse sentido, o processo apreendido em um estudo de caso (seja um indivíduo ou grupo) pode revelar as constituições e determinações históricas, culturais e sociais presentes em outros sujeitos que vivem em condições semelhantes (AGUIAR, 2001, p. 134-140).

5 Tanto os resultados da pesquisa quanto a descrição detalhada das práticas de invenção empregadas durante o doutoramento podem ser acessadas através da tese Práticas de criação musical em ambientes de ensino coletivo aplicando processos heurísticos: uma teoria substantiva (NAZARIO, 2017), disponivel em http://repositorio.unicamp.br/handle/REPOSIP/322091. 
dessa metodologia na área da música, embora perfeitamente possível, ainda não é uma prática comum no Brasil, sendo relevante, assim, apresentar suas possibilidades e potencialidades à pesquisadores interessados em utilizarem outras alternativas de coleta e análise de dados, principalmente àqueles que pretendem elaborar uma teorização envolvendo pesquisa qualitativa.

\section{O que é a Grounded Theory?}

Traduzida em português como "Teoria Fundamentada"6, a Grounded Theory é uma metodologia de pesquisa concebida para facilitar a geração e o desenvolvimento de teorias no contexto da pesquisa social. Idealizada pelos sociólogos americanos Barney Glaser e Anselm Strauss através da publicação do livro The Discovery of Grounded Theory: Strategies for Qualitative Research (1967), trata-se de uma metodologia direcionada às ciências sociais, porém aberta a quaisquer áreas em que haja interesse em investigar fenômenos sociais, especialmente se os estudos estão fundamentados em dados qualitativos (GLASER; STRAUSS, 1967, p. vii-viii).

Os procedimentos da Grounded Theory são projetados para desenvolver um conjunto bem integrado de conceitos que forneçam uma explicação teórica dos fenômenos sociais em estudo (STRAUSS; CORBIN, 1990, p. 5). Os conceitos são a unidade básica de análise e são rotulados por meio do exame de eventos, acontecimentos e incidentes que indicam ou representam o fenômeno observado. Os conceitos que pertencem a um mesmo fenômeno são agrupados em categorias, formando uma abstração mais profunda que fornece os meios pelos quais uma teoria pode ser integrada (ibid., p. 7). Tanto os conceitos quanto as categorias são alcançados através de processos de codificação, os quais consistem em separar, comparar, relacionar e unificar os dados, criando, assim, um arcabouço central que possibilita a geração da teoria (para maiores detalhes, ver subcapítulo Métodos e procedimentos da Grounded Theory realizados durante a pesquisa de doutoramento).

\section{Questões epistemológicas envolvidas na Grounded Theory}

A concepção de qualquer metodologia é indissociável da relação homem/mundo e das possibilidades do conhecimento humano sobre a realidade. Tais instâncias são produzidas socialmente e historicamente em uma relação dialética, uma vez que expressam questões concretas presentes na vida material dos homens (GONÇALVES, 2001, p. 113; AGUIAR, 2001, p. 129). A Grounded Theory - como uma metodologia que surgiu da união de autores pertencentes a duas diferentes escolas de sociologia (Columbia e Chicago7), mas os quais criticavam veemente o excesso de abstração teórica,

\footnotetext{
6 Ou ainda "Teoria Fundamentada nos dados" "Teoria Embasada", "Teoria Emergente" ou "Teoria Enraizada" (LEITE, 2015, p. 76).

7 A perspectiva teórico-filosófica da Universidade de Columbia se caracteriza pela metodologia quantitativa proposta por Paul Lazarsfeld e por teorias uteis de médio alcance proposta por Robert K. Merton (GLASER, 1967, p. vii), enquanto que a tradição de Chicago está associada à pesquisa qualitativa orientada por vieses interacionistas e pragmáticos (LEITE, 2015, p. 76).
} 
por vezes não condizente com a realidade do mundo social - não poderia deixar de ser parte desse contexto histórico. A Grounded Theory é considerada um método interpretativo de pesquisa, buscando compreender a realidade a partir dos significados construídos pelos envolvidos durante suas experiências de vida (MORGAN; SMIRCICH, 1980 apud BANDEIRA-DE-MELLO, 2002, p. 69). Em contrapartida, Denzin a define como uma metodologia pós-positivista por enfatizar uma visão de mundo em termos de causas e efeitos (DENZIN, 1994, p. 508). Strauss e Corbin, contudo, advertem que o principal objetivo dos processos de codificação propostos pela Grounded Theory é obter um melhor entendimento sobre o fenômeno, capturando a dinâmica do fluxo de eventos e a natureza complexa de suas relações (STRAUSS; CORBIN, 1998, p. 129):

... não estamos falando em linguagem de causa e efeito. Isto é muito simplista... O resultado se aproxima de uma discussão que direciona o leitor a uma trilha complexa de inter-relações, cada uma seguindo seu padrão, explicando o que está acontecendo. (STRAUSS; CORBIN, 1998, p.130)

Explicar ou prever um fenômeno não deve ser entendido à luz de uma visão positivista. Cânones da ciência como validade interna, replicabilidade e generalização não devem ignorados, mas reinterpretados na perspectiva proposta pela Grounded Theory, conforme o quadro 1:

\begin{tabular}{c|c|c} 
Cânones da Ciência & Visão positivista & Visão da Grounded Theory \\
\hline VALIDADE INTERNA & $\begin{array}{c}\text { Corresponde ao grau de } \\
\text { ajustamento (fit) da teoria à } \\
\text { realidade. }\end{array}$ & $\begin{array}{c}\text { A realidade é socialmente construída } \\
\text { por meio da percepção dos indivíduos, } \\
\text { e identificada pelo pesquisador através } \\
\text { dos dados coletados. }\end{array}$ \\
\hline $\begin{array}{c}\text { CONFIABILIDADE } \\
\text { (Replicabilidade) }\end{array}$ & $\begin{array}{c}\text { Quando os resultados de um } \\
\text { experimento são alcançados } \\
\text { em outras tentativas, dado que } \\
\text { existe uma única realidade, são } \\
\text { considerados mais válidos. }\end{array}$ & $\begin{array}{c}\text { Impossibilidade de recriar experimentos } \\
\text { controlados nos contextos } \\
\text { organizacionais. O comportamento } \\
\text { humano não é regido por leis universais } \\
\text { que geram resultados iguais. A } \\
\text { confiabilidade é o grau de consistência } \\
\text { entre os resultados do estudo e os dados } \\
\text { coletados. }\end{array}$ \\
\hline VALIDADE EXTERNA & $\begin{array}{c}\text { Refere-se à medida na qual os } \\
\text { resultados podem ser aplicados } \\
\text { (Generalização) }\end{array}$ & $\begin{array}{c}\text { A proposta da Grounded Theory é } \\
\text { especificar as condições em que } \\
\text { ocorrem determinados eventos e } \\
\text { suas consequências. Quanto maiores } \\
\text { às variações incorporadas nos dados, } \\
\text { mais diferentes serão as condições }\end{array}$ \\
& $\begin{array}{c}\text { ponferidos populaçes). } \\
\text { contempladas, e mais geral será a teoria } \\
\text { substantiva construída. }\end{array}$ \\
\hline
\end{tabular}

Quadro 1: Como a Grounded Theory interpreta os cânones da ciência, considerando a comparação de seus resultados com a literatura científica estabelecida. Fonte: Adaptado de Merrian (1998) e Strauss e Corbin (1998), citados por Bandeira-de-Mello (BANDEIRA-DE-MELLO, 2002: 84).

Quanto à validade interna, a visão positivista dá ênfase a coerência da teoria com conhecimentos préestabelecidos, enquanto para a Grounded Theory a realidade é a 
própria base sobre a qual se coleta os dados. Estes constituem indicadores ou imagens da realidade, sendo o campo pesquisado pertencente a esta, os dados coletados serão inerentes a esta. A Grounded Theory não questiona a pertinência ou a coerência dos fenômenos que analisa em relação à realidade na qual eles se inserem e tira suas constatações unicamente a partir da ocorrência dos mesmos. No tocante à confiabilidade, a visão positivista diz respeito a capacidade de predição de resultados em circunstancias de outros contextos além daquele experimentado para a coleta de dados. Já na Grounded Theory, a confiabilidade diz respeito unicamente a coerência relativa entre os dados coletados e o resultado final. Como última instância, a validade externa, ou seja, generalização, a visão positivista considera a capacidade de extrapolar resultados para outros contextos, ou seja, uma extensão natural do que considera confiabilidade, a replicabilidade. No contexto da Grounded Theory, o ambiente externo, sendo considerado aquele que está fora do domínio que gerou o universo de dados dos experimentos, é inatingível a partir do domínio interno pesquisado. A única maneira através da qual se pode chegar ao ambiente externo é refazendo a pesquisa, porém, ampliando em natureza e qualidade os dados a serem obtidos, os casos abrangidos e os desvios considerados, sendo a partir das maiores variações que se pode alargar o domínio em observação e análise.

\title{
4. Grounded Theory de Glaser versus Grounded Theory de Strauss e Corbin
}

A Grounded Theory não possui apenas uma linha de ação. No decorrer dos anos essa metodologia passou por modificações consideráveis quando Glaser e Strauss, ao finalizarem a parceria, deram continuidade à sistematização do método, originando, duas vertentes: a de Glaser e a de Strauss e Corbin ${ }^{8}$ :

\begin{abstract}
... Glaser ensinou Grounded Theory a estudantes de doutorado na UCSF [Universidade da Califórnia]. Ulteriormente ele deixou o ambiente universitário. Strauss continuou ensinando e fazendo pesquisa na UCSF, incluindo cursos de metodologia qualitativa.

Parece lógico que, ao trabalhar com outros colegas e ao longo do tempo, Strauss desenvolveria seu próprio estilo ao utilizar a Grounded Theory. Isto não significa que ele tenha se separado da [própria] metodologia que desenvolveu com Glaser, mas ele tinha suas próprias técnicas e maneiras de pensar sobre os dados ao realizar as análises. (STRAUSS; CORBIN, 2015, p. 6-7)
\end{abstract}

Em sua parceria com Corbin, Strauss publicou o livro Basics of Qualitative Research: Grounded Theory Procedures and Techniques (STRAUSS; CORBIN, 1990), e Basics of Qualitative Research: Techniques and Procedures for Developing Grounded Theory (STRAUSS; CORBIN, 1998, 2008, 2015), firmando alguns de seus ideais sobre o método. Segundo Rennie, há alguns elementos fundamentais da Grounded Theory que tan-

\footnotetext{
8 Há ainda a vertente proposta por Charmaz (2009) denominada Grounded Theory construtivista, a qual evidencia fortemente o processo interpretativo do pesquisador. Tal vertente foi fortemente criticada por Glaser no artigo: Constructivist Grounded Theory? (GLASER, 2002).

9 Na publicação de 2015 Strauss já havia falecido.
} 
to Glaser quanto Strauss ainda compartilhavam em suas publicações, sendo estes: (a) análise comparativa constante, (b) memorandos teóricos, (c) processos de codificação, (d) amostragem teórica e (e) sensibilidade teórica (RENNIE, 1998 apud BULAWA, 2014, p. 152). No entanto, os autores seguem abordagens e linhas diferentes de pensamento conforme apresentado no quadro 2:

\begin{tabular}{c|c} 
Glaser & Strauss e Corbin \\
\hline $\begin{array}{c}\text { Método analítico indutivo. Focaliza } \\
\text { exclusivamente nas situações advindas dos } \\
\text { grupos estudados. }\end{array}$ & $\begin{array}{c}\text { Método analítico indutivo e dedutivo. } \\
\text { Comparando as situações com exemplos } \\
\text { externos, permitindo ao pesquisador validar ou } \\
\text { não suas interpretações. }\end{array}$ \\
\hline $\begin{array}{c}\text { A revisão de literatura só pode acontecer após } \\
\text { o desenvolvimento da teoria, uma vez que esta } \\
\text { deve ser fundamentada exclusivamente em dados } \\
\text { empíricos. }\end{array}$ & $\begin{array}{c}\text { A revisão de literatura pode também acontecer } \\
\text { durante o processo de análise (sem utiliza-la } \\
\text { como dados per se) para estimular a sensibilidade } \\
\text { teórica do pesquisador. }\end{array}$ \\
\hline $\begin{array}{c}\text { O pesquisador não deve ter experiência na } \\
\text { área específica de estudo ou, caso tenha, deve } \\
\text { procurar suspender o que já sabe, para não } \\
\text { influenciar a coleta através de ideias pré- } \\
\text { concebidas. }\end{array}$ & $\begin{array}{c}\text { As experiências pessoais e profissionais são } \\
\text { importantes recursos que permitem ao } \\
\text { pesquisador obter uma maior sensibilidade } \\
\text { teórica, obtendo rapidamente insights e } \\
\text { entendimentos sobre os fenômenos. }\end{array}$ \\
\hline
\end{tabular}

Quadro 2: Propostas de abordagem da Grounded Theory segundo Glaser / Strauss e Corbin (COONEY, 2010, p. 19-21; BULAWA,

$$
\text { 2014, p. 149-152). }
$$

Do ponto de vista metodológico, os autores apresentam duas diferentes propostas de perscrutação dos dados. Glaser sugere dois tipos processos de codificação: substantiva e teórica, enquanto Strauss e Corbin propõem três: codificação aberta, axial e seletiva (COONEY, 2010, p. 20). Obviamente as diferenças aqui pontuadas não se restringem somente a estas codificações, uma vez que ambos os autores deram continuidade às suas publicações, refinando constantemente a metodologia e especificando suas abordagens de acordo com suas vertentes ${ }^{10}$.

Durante a pesquisa de doutorado em questão, elegemos a vertente epistemológica proposta por Strauss e Corbin (1998), não apenas por subscrevermos as linhas de pensamento desses autores, mas também por não concordarmos com a perspectiva proposta por Glaser que assume uma visão mais positivista na medida que compreende que a teoria emergente deve (ou deveria) ser o resultado de uma análise imparcial e objetiva dos dados, pois estes devem "falar por si":

O poder e o arrebatamento de uma teoria fundamentada nos dados $100 \%$ emergente me emocionou pessoalmente com prospectos. Então eu escrevi três monografias sobre como a vida real acontece. Elas foram fáceis de escrever pois não havia conjecturas, apenas conceitualização dos dados. Elas [as monografias] quase se escreveram por si mesmas assim que os dados (conceitualizados) vinham até mim (GLASER, 2016, p. 5).

\footnotetext{
10 Dentre as publicações de Glaser, podemos citar: Theoretical Sensitivity (1978), Emergence Versus Forcing (1992), More Grounded Theory Methodology (1994), Gerund Groundede Theory (1996), Doing Grounded Theory (1998), Grounded Theory Perspective (2001, 2003), entre outras. Dentre as publicações de Strauss, podemos citar: Qualitative Analysis for Social Scientists (1987), Grounded Theory Research: Procedures, Canons and Evaluative Criteria (1990), Grounded Theory Methodology (1994), Analytic Ordering for Theoretical Purposes (1996), entre outras.
} 
Em outra direção, Strauss e Corbin assumem a subjetividade do pesquisador durante processo de construção do arcabouço teórico:

Uma teoria não é a formulação de algum aspecto descoberto de uma realidade pré-existente 'lá fora', pensar deste modo é tomar uma posição positivista que[...], rejeitamos, assim como fazem a maioria dos pesquisadores qualitativos... teorias são interpretações realizadas a partir de determinadas perspectivas adotadas ou procuradas por pesquisadores. Dizer que uma determinada teoria é uma interpretação - e, portanto, falível - não significa negar que decisões possam ser feitas sobre a solidez ou provável utilidade dela. (STRAUSS; CORBIN; 1994, p. 279).

A abordagem epistemológica proposta por Strauss e Corbin é fortemente influenciada pelo pragmatismo de Dewey - entendendo-se que o conhecimento é originado através de ações e interações - bem como pela tradição do interacionismo simbólico (DEWEY, 1929 apud STRAUSS; CORBIN, 2015, p. 18-19) - constituindo uma perspectiva teórica que possibilita a compreensão do modo como os indivíduos interpretam e atribuem significados aos objetos e interações, e como tal processo de interpretação conduz o comportamento individual em situações específicas (CARVALHO et al., 2010, p. 148). O interacionismo simbólico confere a perspectiva de que a sociedade, a realidade e o indivíduo são construídos por meio de interação, sendo esta dinâmica e interpretativa (CHARMAZ, 2009, p. 21).

Com o objetivo de compreender o fenômeno social, Strauss e Corbin propõem direcionamentos ao analista, o qual deve procurar responder "o que é (o fenômeno), quando, onde, porque, como ele ocorre e quais as suas consequências". Tais questionamentos permitem aliar estrutura - as condições ${ }^{11}$ que criam as circunstâncias nas quais os problemas ou eventos relacionados ao fenômeno surgem - e processo - as ações/ interações em resposta a certos problemas e questões (STRAUSS; CORBIN, 1998, p. 127), possibilitando ao pesquisador a compreensão da dinâmica e complexidade envolvida no fenômeno social analisado. Strauss e Corbin entendem o fenômeno como uma importante ideia analítica que emerge dos dados:

Ao procurarmos pelos fenômenos nos dados, buscamos padrões repetidos de acontecimentos, eventos ou ações/interações que representam o que as pessoas fazem ou dizem, sozinhas ou em grupo, em resposta a problemas e situações nas quais elas se encontram (STRAUSS; CORBIN, 1998, p. 130).

Os fenômenos são representados por conceitos, os quais atuam como blocos de construção da teoria (STRAUSS; CORBIN, 1998, p. 101). A teoria deve ser entendida como "um conjunto de conceitos bem desenvolvidos ligados por relações, as quais constituem uma estrutura integrada que pode ser usada para explicar ou prever um fenômeno" (STRAUSS; CORBIN, 1998, p. 15). Teorizar, portanto, implica proporcionar mais do que um entendimento sobre o fenômeno, a teoria permite explicar e prever eventos, proporcionando guias para a ação (STRAUSS; CORBIN, 1998, p. 25). 


\section{Métodos e procedimentos da Grounded Theory realizados durante a pesquisa de doutorado}

\subsection{Estruturação dos dados}

Seguindo, em parte, os critérios adotados por Silva, os depoimentos coletados durante a pesquisa empírica foram organizados conforme a seguinte estrutura (Fig. 1):

Negrito: célula central que representa o código

"Eu fiz um pouco de canto lirico, mas a professora era extremamente rígida, ela não sorria nunca, e ai eu falei: eu não nasci pra isso" (L1, AULA 10, DSC 1115, 10:07)

Fragmento do texto extraido do discurso

Siglas utilizadas:

L1 (L2, L3 etc.) = Laboratório 1 (Laboratório 2, Laboratório 3 etc.)

$\mathrm{PL}=$ Prè-laboratório

E1 (E2, E3 etc.) = Estudante 1 (Estudante 2, Estudante 3 etc.)

DSC 1115, 10:07 = Registro da gravação e tempo onde se encontra o relato na gravação audiovisual.

E3P1 = Relato retirado do questionário (Estudante 3, Página 1)

Fig. 1: Estrutura dos depoimentos (SILVA, 2010, p. 46)

Para fins de classificação, os depoimentos foram dispostos de acordo com o tema em discussão (Quadro 3):

\section{Ex1: Depoimentos relacionados à formação musical}

"Eu fiz um pouco de canto lírico, mas a professora era extremamente rígida, ela não sorria nunca, e aí eu falei: eu não nasci pra isso" (L1, AULA 10, DSC 1115, 10:07)

"Piano eu não tinha em casa e não tinha dinheiro pra comprar, então não tinha como continuar, e fora que quando eu comecei, que eu fiz essa primeira aula, o primeiro contato de aula com música foi com o piano porque tinha uma professora minha de escola que dava aula de piano, mas eu acho que a hora que eu vi partitura eu entrei em pânico, eu nunca vou saber isso, então eu desisti" (L1, AULA 10, DSC 1115, 8:48)

\section{Ex2: Depoimentos relacionados às criações musicais}

"Não pude improvisar como eu queria pelo meu baixo conhecimento" (PL, E3P1)

"Me senti à vontade na hora de cantar a nota, mas na hora de improvisar tinha muita coisa passando na minha cabeça, porém não conseguia passar para o instrumento" (PL, E11P1)

Quadro 3: Exemplo de classificação dos depoimentos conforme o tema em discussão

A partir dessa estruturação, os dados foram analisados adotando-se os seguintes métodos: 


\subsection{Exame microscópico dos dados}

O exame microscópico dos dados (ou microanálise) é uma análise linha-a-linha necessária no começo de um estudo para gerar as categorias iniciais, sugerindo, assim, suas relações (STRAUSS; CORBIN, 1998, p. 57). As categorias são representadas por conceitos que representam o fenômeno, formando blocos de construção da teoria (STRAUSS; CORBIN, 1998, p. 101). Realizar uma microanálise consiste, então, em realizar um cuidadoso escrutínio dos dados para identificar os conceitos e categoriza-los em termos de propriedades e dimensões (STRAUSS; CORBIN, 1998, p. 71). As propriedades são as características de uma categoria, dando-a significado e delineação. As dimensões dizem respeito a como as propriedades gerais de uma categoria variam (STRAUSS; CORBIN, 1998, p. 101). Para identificar os conceitos o pesquisador, ao realizar a microanálise, deve escutar cuidadosamente o que os participantes dizem e como eles interpretam os fatos. Nessa etapa podem surgir hipóteses provisionais (questionamentos sobre como os conceitos se relacionam ${ }^{12}$ ), permitindo obter um olhar mais analítico sobre as informações relatadas pelos respondentes, conforme exemplo abaixo (Quadro 4):

Depoimento: "Eu estudei 10 anos no conservatório, eu não cheguei onde eu queria chegar e hoje eu tenho dificuldade no popular". (L1, AULA 1, E4, DSC 8098 , 4:19)

\begin{tabular}{c|c} 
Depoimento & Análise \\
\hline Eu estudei 10 anos no conservatório... & $\begin{array}{c}\text { O que o participante entende por conservatório? } \\
\text { A sua experiência de aprendizagem foi realizada } \\
\text { realmente nesse tipo de instituição? Por que } \\
\text { o participante culpa a instituição pelas suas } \\
\text { dificuldades? }\end{array}$ \\
\hline$\ldots$ eu não cheguei onde queria chegar... & $\begin{array}{c}\text { Onde ele queria chegar? Ele queria desenvolver } \\
\text { algum aspecto técnico-musical (percepção, } \\
\text { improvisação etc.)? }\end{array}$ \\
\hline$\ldots$ e hoje eu tenho dificuldade no popular. & $\begin{array}{c}\text { O que o participante entende por música } \\
\text { popular? Que tipo de dificuldade ele tem? Por } \\
\text { que o participante não conseguiu dominá-la? } \\
\text { Qual a relação entre a sua aprendizagem no } \\
\text { conservatório e as suas dificuldades quanto à } \\
\text { música popular? }\end{array}$ \\
\hline
\end{tabular}

Quadro 4: Microanálise

Observa-se que o participante atribui significados e que estes nem sempre estão claros ao pesquisador. Segundo Strauss e Corbin, nesses casos, o investigador deve realizar comparações teóricas, ou seja, deve procurar por demais exemplos (podendo-se recorrer à literatura) de maneira a clarificar, ao menos em parte, os significados atribuídos pelos participantes. As comparações teóricas permitem estimular o pensamento sobre as propriedades e dimensões direcionando novas amostragens teóricas 
(STRAUSS; CORBIN, 1998, p. 78). Ao comparar o depoimento anterior com um novo depoimento, temos:

\section{DEPOIMENTO 1}

"Eu estudei 10 anos no conservatório, eu não cheguei onde eu queria chegar e hoje eu tenho dificuldade no popular" (L1, AULA 1, E4, DSC 8098, 4:19)

\section{DEPOIMENTO 2}

"A experiência com conservatório eu acho muito ruim, eu acho um desastre. Em geral a experiência com o conservatório é ruim, eu não sei se hoje está melhorando isso, mas a impressão que eu tenho é que não está, porque desenvolve a leitura e não desenvolve a percepção" (L1, AULA1, E1, DSC 8100, 5:18)

O depoimento 2 esclarece um pouco mais os problemas enfrentados por ambos os respondentes. Diversos questionamentos surgem em torno destes depoimentos, tais como:

- A dificuldade em música popular mencionada no depoimento 1 tem relação com o não desenvolvimento da percepção mencionado no depoimento 2? O participante 1 tem dificuldades devido ao pouco desenvolvimento da percepção musical?

- O conservatório, em ambos os depoimentos, diz respeito ao mesmo tipo de instituição?

- Por que ambos participantes demonstram insatisfação com a metodologia de ensino aplicada a eles? As metodologias que eles vivenciaram eram similares?

Vemos acima um exemplo do caminho analítico percorrido no processo de microanálise, a qual, frente a novos depoimentos, irá permitir a identificação dos primeiros códigos conceituais rotulados durante o processo de codificação aberta.

\subsection{Codificação aberta}

"A codificação aberta é o processo analítico no qual os conceitos ${ }^{13}$ são identificados e suas propriedades e dimensões são descobertas nos dados" (STRAUSS; CORBIN, 1998, p. 101). Por meio da análise comparativa constante, os dados são separados e comparados, procurando-se por similaridades e diferenças. Códigos similares (ou com significados relacionados) advindos dos relatos, acontecimentos e ações/interações, são agrupados em conceitos mais abstratos denominados categorias (STRAUSS; CORBIN, 1998, p. 102). Alguns códigos podem ser identificados in vivo, ou seja, retirados a partir de expressões utilizadas pelos próprios participantes. Em outros, o próprio pesquisador atribui rótulos de acordo com suas propriedades gerais, conforme quadro 5 : 


\begin{tabular}{|c|c|c|}
\hline Depoimentos & Códigos & Propriedades gerais \\
\hline $\begin{array}{l}\text { "A cada sessão da oficina percebo coisas em } \\
\text { mim, capacidades que tenho e não havia } \\
\text { percebido. Sinto que estou desenvolvendo } \\
\text { minha intuição musical" (L3, AULA 3, E5P3) }\end{array}$ & \multirow{3}{*}{$\begin{array}{l}\text { Intuição } \\
\text { (in vivo) }\end{array}$} & \multirow{3}{*}{$\begin{array}{l}\text { Caracteriza-se pela descoberta } \\
\text { de uma performance mais } \\
\text { imaginativa, tendo pouca } \\
\text { intervenção de pensamentos } \\
\text { de controle e crivo durante } \\
\text { realizações criativas }\end{array}$} \\
\hline $\begin{array}{l}\text { "Eu consegui ter uma visão que eu não sabia } \\
\text { que existia, de fazer música com mais liberdade. } \\
\text { Eu acho que na verdade a intuição, talvez eu } \\
\text { até tivesse alguma coisa assim, mas não sabia } \\
\text { que podia" (L2, AULA 6, DSC 5167, 05:31) }\end{array}$ & & \\
\hline $\begin{array}{l}\text { "Sem dúvida traz impacto na minha formação } \\
\text { musical. Na minha opinião, esse deveria ser } \\
\text { o caminho para o aprendizado musical, ou } \\
\text { seja, o caminho intuitivo, natural, vindo } \\
\text { depois disso a teoria para auxiliar e não como } \\
\text { essência" (L3, AULA 3, E2P3) }\end{array}$ & & \\
\hline $\begin{array}{l}\text { "No começo, um pouco tímida, mas aos poucos } \\
\text { fui soltando as notas" (L2, AULA 1, E3P1) }\end{array}$ & \multirow{3}{*}{ Adaptação } & \multirow{3}{*}{$\begin{array}{l}\text { Tem como característica o } \\
\text { confronto com situações novas } \\
\text { vivenciadas pelos participantes, } \\
\text { sendo necessário para isso, } \\
\text { um determinado tempo para } \\
\text { poderem encontrar meios para } \\
\text { resolverem seus problemas. }\end{array}$} \\
\hline $\begin{array}{l}\text { "Em alguns momentos me senti um pouco } \\
\text { intimidada e perdida por não saber o que } \\
\text { viria a seguir, pois eu acostumei a tocar peças } \\
\text { préestabelecidas, mas pouco a pouco sumiam } \\
\text { essas emoções quando eu disfrutava dos sons" } \\
\text { (L1, AULA 1, E1P1) }\end{array}$ & & \\
\hline $\begin{array}{l}\text { "No começo me senti um pouco fora da minha } \\
\text { zona de conforto porque improvisar em } \\
\text { público não é algo que eu estou acostumada a } \\
\text { fazer. No entanto, logo eu me senti à vontade } \\
\text { porque esse foi um exercício bem livre e } \\
\text { gostoso" (L3, AULA 1, E9P1) }\end{array}$ & & \\
\hline
\end{tabular}

Quadro 5: Propriedades gerais de um código

Os códigos podem ser dimensionados de acordo com as variações encontradas nos dados. Segundo Strauss e Corbin, cada código ou categoria geralmente possui mais de uma propriedade ou atributo, permitindo ao pesquisador classificar cada propriedade de acordo com suas dimensões (STRAUSS; CORBIN, 1998, p. 103), conforme exemplificado no quadro 6 : 


\begin{tabular}{|c|c|c|}
\hline Depoimentos & Códigos & Dimensões \\
\hline $\begin{array}{l}\text { "No começo, um pouco tímida, mas aos poucos } \\
\text { fui soltando as notas" (L2, AULA 1, E3P1) }\end{array}$ & \multirow{4}{*}{ Adaptação } & \multirow{2}{*}{$\begin{array}{l}\text { Processos de adaptação } \\
\text { relacionados à timidez. }\end{array}$} \\
\hline $\begin{array}{l}\text { "No começo me senti meio com vergonha, mas } \\
\text { depois fui me soltando e consegui encaixar o } \\
\text { mesmo tom de música" (L2, AULA 1, E5P1) }\end{array}$ & & \\
\hline $\begin{array}{l}\text { "Em alguns momentos me senti um pouco } \\
\text { intimidada e perdida por não saber o que } \\
\text { viria a seguir, pois eu acostumei a tocar peças } \\
\text { préestabelecidas, mas pouco a pouco sumiam } \\
\text { essas emoções quando eu disfrutava dos sons" } \\
\text { (L1, AULA 1, E1P1) }\end{array}$ & & \multirow{2}{*}{$\begin{array}{l}\text { Processos de adaptação } \\
\text { advindos de situações gerando } \\
\text { novas vivências musicais ou } \\
\text { envolvendo imprevisibilidade } \\
\text { no direcionamento musical. }\end{array}$} \\
\hline $\begin{array}{l}\text { "No momento em que me foi solicitado } \\
\text { improvisar uma ideia na percussão me } \\
\text { senti um pouco tenso, pois tocar percussão } \\
\text { acompanhando outro instrumento é algo que } \\
\text { já estou mais acostumado. Solo, eu achei um } \\
\text { pouco desconfortável, mas foi só no início, } \\
\text { depois deixei rolar" (L3, AULA 3, E5P1) }\end{array}$ & & \\
\hline
\end{tabular}

Quadro 6: Dimensões do código rotulado como Adaptação

Uma vez identificado os códigos com suas propriedades e dimensões, por meio da codificação axial, estes são relacionados e/ou reestruturados em categorias e subcategorias, permitindo, assim, um maior entendimento quanto à complexidade dos fenômenos observados.

\subsection{Codificação axial}

É o processo que consiste em relacionar as categorias às suas subcategorias, utiliza-se o termo 'axial' porque a codificação ocorre em torno de um eixo de uma categoria, ligando as categorias em nível de propriedades e dimensões (STRAUSS; CORBIN, 1998, p. 123).

A partir da codificação axial os dados (anteriormente fragmentados durante a codificação aberta), são remontados para formar uma explicação mais precisa sobre o fenômeno, não significando, contudo, que tais processos precisam necessariamente ocorrer em passos analíticos sequenciais (STRAUSS; CORBIN, 1998, p. 124). A codificação axial permite relacionar estrutura e processo, investigando as condições causais (conjuntos de eventos que influenciam um fenômeno), intervenientes (condições que alteram o impacto das condições causais) e contextuais (conjunto específico de condições que se inter-relacionam criando circunstâncias ou problemas as quais as pessoas respondem através de ações/interações), e como estas podem influenciar as ações dos indivíduos. Com isso, o pesquisador pode captar a dinâmica envolvendo a natureza dos eventos (STRAUSS; CORBIN, 1998, p. 127-131). O investigador pode, quando apropriado, contextualizar o fenômeno em um contexto micro (relacionado a um escopo delimitado e específico) ou macro (relacionado a um escopo geral), se tais eventos 
emergirem dos dados (STRAUSS; CORBIN, 1998, p. 181). Em muitos casos, os relatos evidenciam uma ou mais recorrências de códigos, permitindo ao pesquisador correlacioná-los, possibilitando uma maior compreensão quanto aos elementos complexos presentes no fenômeno. A figura abaixo (Fig. 2) apresenta uma imagem gerada pelo software Atlas. $\mathrm{ti}^{14}$, originada a partir da relação entre os diferentes códigos presentes em um dos depoimentos:

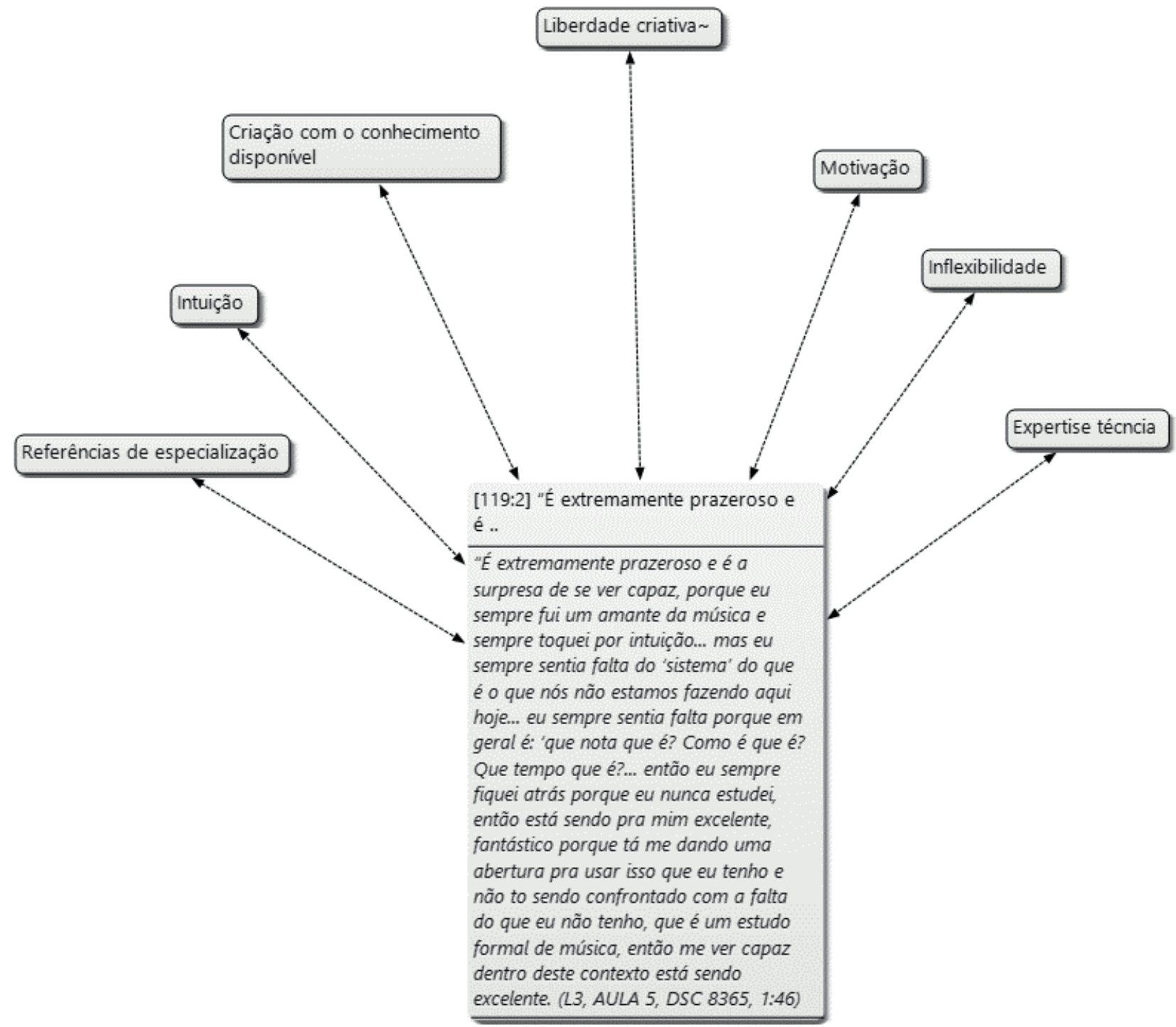

Fig. 2: Diferentes códigos presentes em um único depoimento

Os códigos selecionados foram identificados por meio do procedimento de codificação aberta, seguindo diretrizes propostas por Strauss e Corbin (1998), conforme exemplificado a seguir em marcações em negrito e entre colchetes: 
"É extremamente prazeroso e é a surpresa de se ver capaz, porque eu sempre fui um amante da música e sempre toquei por intuição... mas eu sempre sentia falta do 'sistema' [referências de especialização] do que é o que nós não estamos fazendo aqui hoje... eu sempre sentia falta porque em geral é: 'que nota que é? Como é que é? Que tempo que é?... então eu sempre fiquei atrás porque eu nunca estudei, então está sendo pra mim excelente, fantástico, porque tá me dando uma abertura [liberdade criativa] pra usar isso que eu tenho [criação com o conhecimento disponível] [intuição] e não to sendo confrontado [inflexibilidade] com a falta do que eu não tenho, que é um estudo formal de música [expertise técnica], então me ver capaz dentro deste contexto está sendo excelente. [motivação] (L3, AULA 5, DSC 8365, 1:46)

O quadro abaixo apresenta as palavras-chave retiradas do depoimento e suas subsequentes interpretações ${ }^{15}$ :

\begin{tabular}{|c|c|}
\hline Palavras-chave & Interpretação do pesquisador \\
\hline $\begin{array}{c}\text {...mas eu sempre sentia falta do 'sistema'... eu } \\
\text { sempre sentia falta porque em geral é: 'que nota } \\
\text { que é? Como é que é? Que tempo que é?... }\end{array}$ & $\begin{array}{c}\text { O "sistema" diz respeito às Referências de } \\
\text { especialização, ou seja, aos modelos adotados } \\
\text { como fonte de aperfeiçoamento. }\end{array}$ \\
\hline $\begin{array}{l}\text {...está sendo pra mim excelente, fantástico, } \\
\text { porque tá me dando uma abertura... }\end{array}$ & $\begin{array}{c}\text { A "abertura" relaciona-se com a liberdade criativa } \\
\text { que o participante experimentou na oficina de } \\
\text { criação musical. }\end{array}$ \\
\hline ...pra usar isso que eu tenho ... & $\begin{array}{l}\text { "Usar isso que eu tenho" refere-se, em parte, } \\
\text { à criação com o conhecimento disponível, } \\
\text { permitindo ao participante expressar-se } \\
\text { musicalmente com os conhecimentos que } \\
\text { possui e, em parte, à intuição no qual o } \\
\text { participante relata ser sua principal "ferramenta" } \\
\text { de expressão musical. }\end{array}$ \\
\hline ...e não to sendo confrontado... & $\begin{array}{c}\text { "Confrontado" remete a Inflexibilidade quanto ao } \\
\text { uso das Referências e Expertise técnica para a } \\
\text { criação musical. }\end{array}$ \\
\hline $\begin{array}{l}\text {...com a falta do que eu não tenho que é um } \\
\text { estudo formal de música... }\end{array}$ & $\begin{array}{l}\text { Com "estudo formal de música" o participante se } \\
\text { refere às Referências de especialização e expertise } \\
\text { técnica, ou seja, a exigência prévia de determinados } \\
\text { conhecimentos e/ou habilidades específicas. }\end{array}$ \\
\hline $\begin{array}{c}\text {...então me ver capaz dentro deste contexto está } \\
\text { sendo excelente. }\end{array}$ & $\begin{array}{c}\text { "Está sendo excelente" pode indicar motivação por } \\
\text { parte do participante frente a esse contexto. }\end{array}$ \\
\hline
\end{tabular}

Quadro 7: Interpretação do depoimento

Com isso, tornou-se possível inferir determinados vínculos entre os códigos, formando, assim, uma codificação axial. A figura 3, também gerada pelo Software Atlas.ti apresenta as relações constituídas através da análise deste depoimento:

\footnotetext{
15 Ressalta-se que tais interpretações não decorrem somente deste depoimento, mas por meio de comparações teóricas com outros depoimentos, permitindo, assim, obter uma melhor compreensão e acuidade em relação aos incidentes e aos significados dos termos proferidos pelos participantes (STRAUSS \& CORBIN, 1998, p. 80)
} 


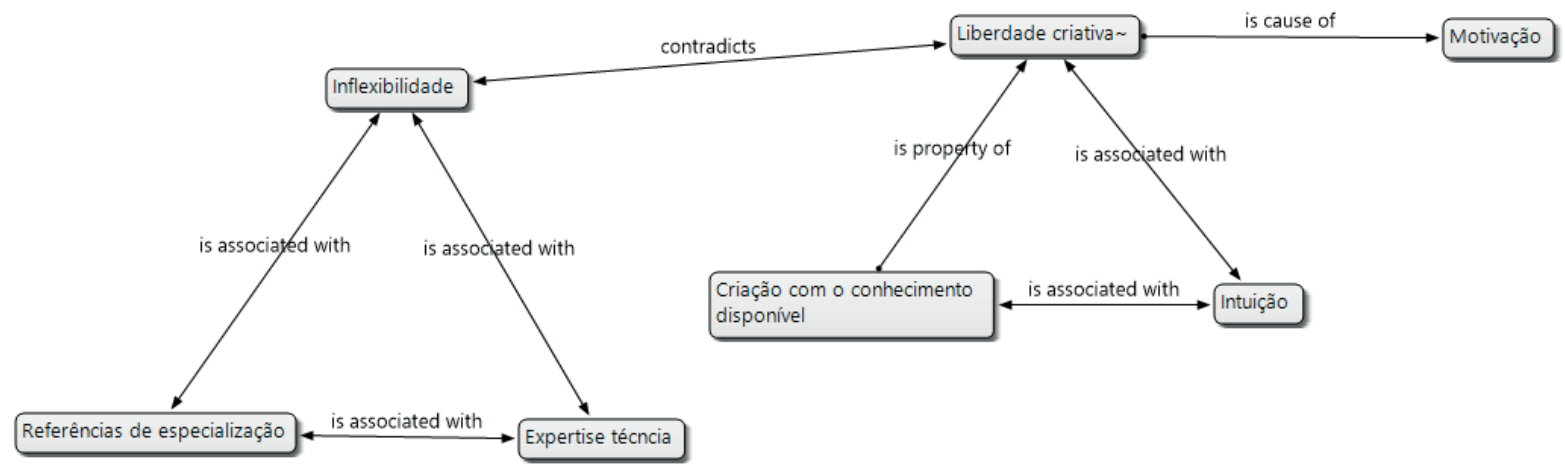

Figura 3: Relação entre códigos de acordo com o depoimento (codificação axial)

Entende-se que a associação das referências de especialização e expertise técnica junto à inflexibilidade, traz uma contradição à liberdade criativa, ou seja, assume-se uma posição contrária à livre expressão, a não ser que esta esteja subordinada a estes sistemas:

“...mas eu sempre sentia falta do sistema...".

Ao vivenciar um contexto permitindo sua livre expressão musical de acordo com o seu conhecimento disponível (propriedade da liberdade criativa), o participante teve a oportunidade de manifestar sua intuição sem o receio de ser confrontado com tais sistemas. Ele percebeu-se capaz de criar dentro destas condições, permitindo-nos associar a liberdade criativa à motivação gerada através da autoeficácia ${ }^{16}$ :

"...está sendo pra mim excelente, fantástico, porque tá me dando uma abertura... me ver capaz dentro deste contexto está sendo excelente..."

Os depoimentos seguiram esse caminho analítico resultando na identificação de categorias e subcategorias anteriormente apresentadas e suas inter-relações com a categoria central.

\subsection{Codificação seletiva}

A codificação seletiva é "o processo de integrar e refinar a teoria" (STRAUSS; CORBIN, 1998, p. 143). As categorias são organizadas em torno de uma categoria central que representa o tema principal da pesquisa (STRAUSS; CORBIN, 1998, p. 144). Strauss sugere que a categoria central deva aparecer frequentemente nos dados, estando as demais categorias relacionadas a esta de maneira lógica e consistente. Ainda, o nome ou frase usada para descrevê-la deve ser abstrato o suficiente para que ela seja utilizada em demais pesquisas que envolvam outras áreas substantivas (STRAUSS, 1987, p. 36). 
$\mathrm{Na}$ pesquisa realizada, elegemos o código "liberdade criativa" como categoria central desse estudo, estando os demais códigos vinculados a esta como categorias ou subcategorias. Os critérios para a escolha da categoria central foram adotados em conformidade com as diretrizes sugeridas por Strauss e Corbin, os quais a atribuem uma capacidade de poder analítico, ou seja, ela deve reunir as demais categorias de forma a apresentar um todo explanatório (STRAUSS; CORBIN, 1998, p. 146). Durante esse estudo de doutorado, observou-se que o termo liberdade (ou sua cognata livre) e palavras associadas ${ }^{17}$ apareceram frequentemente nos dados. Por meio da utilização da ferramenta Word Cruncher disponível no software Atlas.ti, foi possível constatar a recorrência de tais termos em 85 das 283 citações selecionadas, indicando, assim, certa relevância quantitativa deste conceito junto aos casos estudados. A título de exemplo, apresentamos na figura 4 um modelo visual que relaciona a categoria central desse estudo com as demais categorias e subcategorias, sintetizando a teoria substantiva resultante desse estudo:

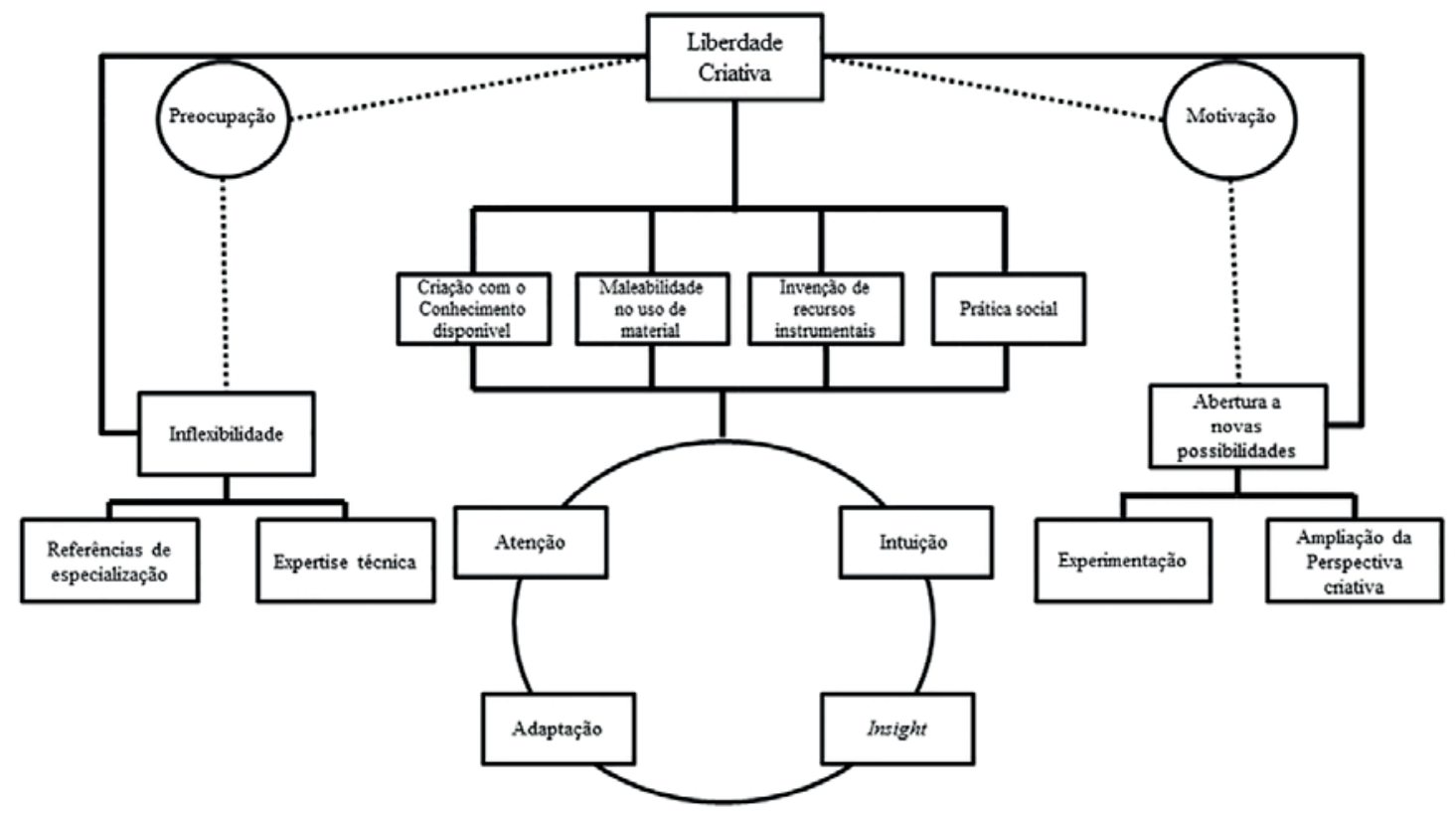

Figura 4: Modelo relacional originado através do processo de codificação seletiva

\subsection{Amostragem e saturação teórica}

Durante a investigação, realizou-se amostragens teóricas, as quais consistem na coleta de dados com base em conceitos derivados da teoria emergente. A partir de tais amostragens, é possível realizar comparações e descobrir variações entre conceitos, dando maior densidade às categorias em termos de propriedades e dimensões (STRAUSS; CORBIN, 1998, p. 201). As amostragens podem ser relacionais ou variacionais, no qual busca-se por incidentes indicando alcance dimensional, ou seja, apresentando variações de um conceito e as relações entre os conceitos (STRAUSS; CORBIN, 1998, p. 210). Nessa pesquisa, por exemplo, algumas variações e relações foram alcançadas 
por meio do emprego de atividades de invenção em contraste às atividades de improvisação idiomática. Com isso procuramos compreender como determinado conceito permanece o mesmo, varia ou se relaciona com outro sob diferentes condições. As amostragens teóricas foram efetivadas até o momento de atingir a saturação teórica, a qual consiste em coletar dados até que mais nenhuma informação relevante apareça. $A$ saturação teórica, portanto, não pode ser definida a priori, pois depende exclusivamente dos dados de pesquisa.

\subsection{Memos e diagramas}

Memorandos (ou memos) são gravações escritas contendo o produto das análises ou direcionamentos ao analista. Diagramas são ferramentas visuais que descrevem as relações entre os conceitos (STRAUSS; CORBIN, 1998, p. 217). Os memorandos e diagramas proporcionam uma coleção de ideias analíticas que podem ser ordenadas, reordenadas e recuperadas de acordo com o esquema teórico envolvido (STRAUSS; CORBIN, 1998, p. 220). Através dos memos o pesquisador pode inferir alguns códigos com suas propriedades e dimensões (notas de codificação), estabelecer hipóteses a serem verificadas (notas teóricas) ou ainda descrever os direcionamentos específicos a serem realizados no decorrer da análise (notas operacionais) (STRAUSS; CORBIN, 1998, p. 227). Durante a pesquisa, esses procedimentos foram utilizados em todas as etapas de codificação. A figura 5 apresenta uma das notas de codificação registrada no software Atlas.ti:

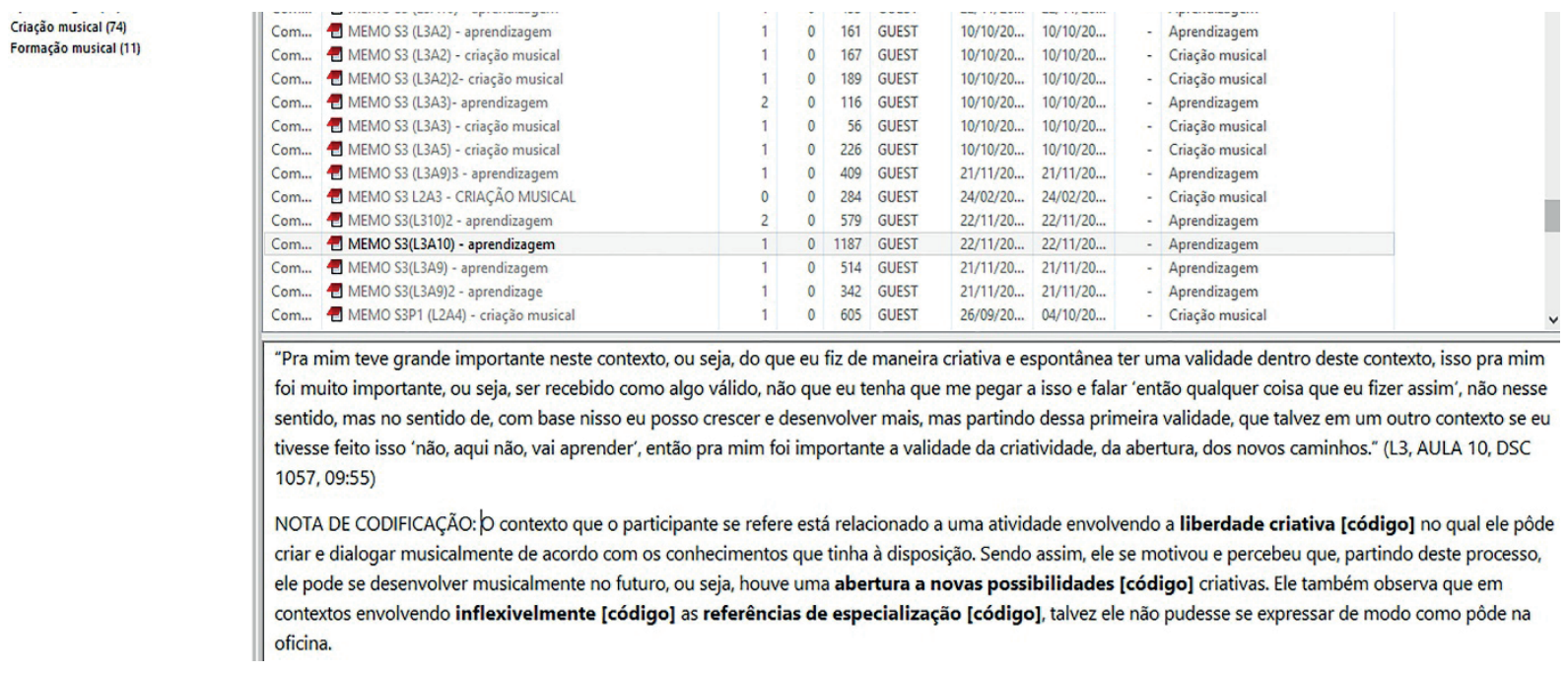

Fig. 5: Nota de codificação

\section{Discussão e conclusão}

Indubitavelmente os métodos e procedimentos apresentados nesse artigo não encerram as possibilidades propostas por essa metodologia. Conforme observam Strauss e Corbin, pesquisadores inventam diferentes procedimentos adaptando os métodos segundo as circunstâncias de seus próprios processos de pensamentos (STRAUSS; CORBIN, 1994, p. 276). Glaser e Strauss, já na primeira publicação dessa metodologia, 
sugerem que a sistematização proposta seja flexível e subordinada à criatividade do pesquisador para construir a teoria substantiva, produto da pesquisa qualitativa. (GLASER; STRAUSS, 1967, p. 8). A Grounded Theory pode ainda ser utilizada parcialmente em conjunto com outro método de pesquisa (Glaser, 2010, p. 2). Charmaz destaca a possibilidade de que o pesquisador possa adaptá-la para a realização de estudos diversos (CHARMAZ, 2009, p. 23). Segundo Strauss e Corbin, os métodos e procedimentos propostos por essa metodologia não precisam, necessariamente gerar teorias, podendo ser utilizados para realizar descrições densas objetivando obter novos conhecimentos (STRAUSS; CORBIN, 1998, p. x).

Observa-se a necessidade de flexibilização no uso dessa metodologia subordinando- a à criatividade do pesquisador e às contingências da pesquisa. Strauss e Corbin destacam que seus métodos não devem ser utilizados de maneira dogmática e rígida, sendo necessário ter espaço suficiente para que o pesquisador possa capturar a essência dos objetos representados (STRAUSS; CORBIN, 1998, p. 129). O pesquisador, então, utiliza os procedimentos de análise de dados de maneira imaginativa e intuitiva, beneficiando-se de insights como um recurso crucial para o desenvolvimento da teoria (GLASER; STRAUSS, 1967, p. 251). Essa ampla gama de possibilidades pode confundir o pesquisador menos atento, pois além de ter que eleger a vertente mais viável e adequada à sua pesquisa (tanto no aspecto metodológico quanto epistemológico), deve, também adequar os métodos e procedimentos propostos às peculiaridades de sua investigação. Se por um lado esse caminho aberto pode apresentar dificuldades iniciais ao seu plano de ação, por outro, reflete uma maleabilidade necessária às ciências humanas, evidenciando uma prática científica em constante construção. Entendemos que tal prática não é negativa, e sim necessária, pois, como bem afirmou Japiassu, uma produção científica acabada (incluindo aqui a ideia de uma metodologia rígida e inflexíve $\left.{ }^{18}\right)$ seria um absurdo epistemológico, deixando de ser científico para converter-se em um dogma imutável (JAPIASSU, 1975, p. 26).

A aplicação da metodologia Grounded Theory nessa pesquisa de doutorado gerou uma teoria substantiva sobre a liberdade criativa em música. Tal teoria introduziu um modelo relacional aliando estrutura e processo (apresentado na figura 4), formando um esquema representativo capaz de evidenciar a maneira como certas condições, ações/ interações e consequências se encontram inter-relacionadas no desenvolvimento criativo. Da análise das performances e dos relatos dos participantes, foram elencados determinados princípios que regem esse modelo, evidenciando os efeitos positivos para a aprendizagem musical ao promover a liberdade criativa. A teoria se constitui como um produto da aplicação dessa metodologia, a qual possibilitou (através de seus métodos e procedimentos) relacionar os significados atribuídos pelos participantes às ações/ interações advindas de suas vivências efetivadas durante as atividades laboratoriais. A partir desses resultados, consideramos que a Grounded Theory se mostrou eficaz durante todo o processo de coleta e análise de dados, bem como na construção da teoria

$18 \quad$ O grifo é nosso. 
substantiva resultante, sendo, portanto, indicada como uma possibilidade metodológica na pesquisa em música.

\section{Agradecimentos}

Agradeço profundamente os professores Dr. José Augusto Mannis (orientador), Dra. Adriana Mendes (coorientadora), bem como os docentes Dr. Ricardo Goldemberg e Dr. Silvio Ferraz pela ajuda e apoio dado a essa pesquisa. Meus agradecimentos ao Dr. Manuel Falleiros, supervisor do Centro de Integração, Documentação e Difusão Cultural (CIDDIC - Unicamp) por possibilitar toda a infraestrutura necessária para a realização da pesquisa empírica. Da mesma forma, sou grato a todos os participantes voluntários que frequentaram os laboratórios de criação musical e contribuíram com seus depoimentos. Por fim, agradeço à Fundação de Amparo à Pesquisa do Estado de São Paulo (FAPESP) pelo suporte dado a essa pesquisa, permitindo divulgá-la no Brasil e exterior.

\section{Referências}

BANDEIRA-DE-MELLO, Rodrigo. Uma teoria substantiva da adaptação estratégica a ambientes turbulentos e com forte influência governamental: o caso das pequenas construtoras de edificações. 2002. 387 f. Tese (Doutorado em Engenharia de Produção). Programa de Pós-graduação em Engenharia de Produção, Universidade Federal de Santa Catarina, Florianópolis.

BANDURA, A. Self-efficacy: The Exercise of Control, New York: Freeman and Company, 1997.

BULAWA, Philip. Adapting Grounded Theory in Qualitative Research: Reflections from

Personal Experience. International Research in Education, v. 2, no 1, p. 145-168, 2014.

CARVALHO, Virgínia Donizete de; BORGES, Lívia de Oliveira; RÊGO, Denise Pereira do. Interacionismo simbólico: origens, pressupostos e contribuições aos estudos em psicologia social. Psicologia, Ciência e Profissão, v. 30, no 1, p. 146-161, 2010.

CHARMAZ, Kathy. A construção da teoria fundamentada: guia prático para análise qualitativa. Trad. Joice Elias Costa. Porto Alegre: ARTMED Editora, 2009.

COONEY, Adeline. Choosing between Glaser and Strauss: an Example. Nurse Researcher, v. 17, no 4, p. 18-28, 2010.

CORBIN, Juliet; STRAUSS, Anselm. Grounded Theory Research: Procedures, Canons, and Evaluated Criteria. Qualitative Sociology, v. 13, no 1, p. 3-21, 1990. 
DENZIN, Norman K. The Art and Politics of Interpretation. In: DENZIN, Norman K.; LINCOLN, Yvonna S. (Eds.). Handbook of Qualitative Reserach. Thousand Oaks: SAGE Publications, 1994, p. 500-515.

DWIVEDI, Yogesh K.; LAL, Banita; WILLIANS, Michael D.; SCHNEBERGER, Scott L.; WADE, Michael. Handbook of Research of Contemporary Theoretical Models in Information Systems. New York: IGI Global, 2009.

GLASER, Barney. The Grounded Theory Perspective: Its Origins and Growth. The Grounded Theory Review, v. 15, no 1, p. 4-9, 2016.

GLASER, Barney; STRAUSS, Anselm. The Discovery of Grounded Theory: Strategies for Qualitative Research. New York: Aldine de Gruyter, 1967.

JAPIASSU, Hilton. O mito da neutralidade científica. Rio de Janeiro: Imago Editora LTDA, 1975.

MANNIS, José Augusto. Processos cognitivos de percepção, análise e síntese atuando no processo criativo: Mímesis de mímesis. Encontro Nacional de Compositores ENCOM, n² 2, 2014, Londrina. Anais... Londrina: Biblioteca Central, 2014. p. 198-225.

NAZARIO, Luciano. Práticas de criação musical em ambientes de ensino coletivo aplicando processos heurísticos: uma teoria substantiva. 2017. 352 f. Tese (Doutorado em Música). Programa de Pós-graduação em Música, Universidade Estadual de Campinas, Campinas.

SCHRÖEDER, Christine da Silva. Educação a Distância e Mudança Organizacional na Escola de Administração da UFRGS: Uma Teoria Substantiva. 2009. 252 f. Tese (Doutorado em Administração). Programa de pós-graduação em Administração da Escola de Administração, Universidade Federal do Rio Grande do Sul, Porto Alegre.

SILVA, Ronaldo da. Leitura cantada: Um caminho para a construção da audiação no músico profissional. 2010. 112 f. (Mestrado em música). Programa de Pós-graduação em Música do Instituto de Artes, Universidade Estadual de Campinas, Campinas.

STRAUSS, Anselm. Qualitative Analysis for Social Scientists. United Kingdom: Cambridge University Press, 1987.

STRAUSS, Anselm; CORBIN, Juliet. Grounded Theory Methodology. In: DENZIN, Norman K.; LINCOLN, Yvonna S. (Eds.). Handbook of Qualitative Research. Thousand Oaks: SAGE Publications, 1994, p. 273-285. 
Basics of Qualitative Research: Techniques and Procedures for Developing Grounded Theory. Thousand Oaks: SAGE publications, 1998.

Basics of Qualitative Research: Techniques and Procedures for Developing Grounded Theory. Thousand Oaks: SAGE publications, 2015. 